\title{
вмJ Global Health TikTok and public health: a proposed research agenda
}

\author{
Marco Zenone, ${ }^{1,2}$ Nikki Ow, ${ }^{1}$ Skye Barbic ${ }^{1,3}$
}

To cite: Zenone M, Ow N, Barbic S. TikTok and public health: a proposed research agenda. BMJ Global Health 2021;6:e007648. doi:10.1136/ bmjgh-2021-007648

Handling editor Seye Abimbola

Received 6 0ctober 2021 Accepted 4 November 2021

Check for updates

(C) Author(s) (or their employer(s)) 2021. Re-use permitted under CC BY-NC. No commercial re-use. See rights and permissions. Published by BMJ.

${ }^{1}$ Faculty of Medicine, Department of Occupational Science and Occupational Therapy, The University of British Columbia, Vancouver, British Columbia, Canada

${ }^{2}$ Faculty of Public Health and Policy, London School of Hygiene and Tropical Medicine, London, UK

${ }^{3}$ Providence Research, Providence Health Care Vancouver, British Columbia, Canada

Correspondence to

Mr Marco Zenone;

marco.zenone@|shtm.ac.uk

\section{INTRODUCTION}

TikTok is a short video sharing social media platform that has grown rapidly since its launch, amassing over 1 billion monthly global users as of September 2021. ${ }^{1}$ Users on TikTok create and engage with algorithmsuggested content related to their interests on a variety of subjects, including health-related or implicated topics. The global growth of TikTok, while offering an engaging experience for users and approach to connecting to diverse people, is accompanied by concerns, such as the quality of health advice offered in videos and sensitive content. In this commentary, we argue that public health is served by paying urgent attention to the potential health-related implications and opportunities of TikTok and suggest a research agenda to inform decision-makers, health providers, researchers and the public.

\section{PUBLIC HEALTH-RELATED CONCERNS AND RESEARCH FOCUS AREAS \\ Health-harming product promotion}

Early research illustrates products detrimental to health, such as alcohol or vaping items, are widely viewed and portrayed positively on TikTok. For example, a study found that the top 100 videos with the \#alcohol hashtag were viewed $291999 \quad 100$ times and 98\% portrayed alcohol use in a positive manner. ${ }^{2}$ In the past, health-harming industries have used influencers-defined as influential persons online-to promote harmful products. The vaping company JUUL employed Instagram influencers and affiliate marketers to promote their products that now constitute a public health crisis. ${ }^{3}$ Investigation is needed to explore the marketing, platform facilitators and financial drivers behind the portrayal or promotion of such products on TikTok. Researchers may consider the commercial determinants of health ${ }^{4}$ to frame their research questions and conceptualise

\section{Summary box}

TikTok is a short video sharing social media platform that has grown rapidly since its launch, amassing over 1 billion monthly global users as of September 2021.

We argue that public health is served by paying urgent attention to the potential health-related implications of TikTok and suggest research agenda to inform decision-makers, health providers, researchers and the public

- Specific research priorities include investigating health-harming product promotion, medical advice/ illness portrayal, dis/misinformation spread, sensitive or hateful content dissemination, problematic usage or addiction and platform corporate activity.

health-harming industry motives and prior advertising strategies on social media.

\section{Medical advice and health/illness portrayal}

There exists evidence that TikTok influencers or users are offering medical-related advice or discuss health-related topics that receive significant engagement. For example, table 1 denotes the popularity of various health-related hashtags, such as \#MentalHealth, which received over 17 billion views on tagged videos. ${ }^{5}$ Several studies document the portrayal of certain health-related topic education, such as recovering from eating disorders ${ }^{6}$ and sexual education. ${ }^{7}$ However, the quality of the information offered, qualifications of the persons offering advice or their conflicts of interest, are largely unknown. A recent study on diabetes information on TikTok found that while good actors, such as qualified organisations, gave evidence-based information, those made by for-profit groups had poor quality. ${ }^{8}$ A study evaluating medical information related to acne identified that the top 100 videos with the \#acne hashtag had 'information with serious to potentially important shortcomings'. ${ }^{9}$ Research is needed to understand who is giving medical advice, the quality of the advice offered, how 
Table 1 *Number of views on TikTok videos with healthrelated hashtags

\begin{tabular}{lc}
$\begin{array}{l}\text { Condition or health-related topic } \\
\text { hashtag }\end{array}$ & $\begin{array}{c}\text { Total number of } \\
\text { tagged-video } \\
\text { hashtag views }\end{array}$ \\
\hline \#Covid19 & 83.6 billion \\
\hline \#MentalHealth & 17 billion \\
\hline \#Pregnancy & 16.4 billion \\
\hline \#Cancer & 11.4 billion \\
\hline \#Sleep & 10.8 billion \\
\hline \#Anxiety & 9 billion \\
\hline \#ADHD & 7.1 billion \\
\hline \#Vaccine & 7 billion \\
\hline \#Autism & 4.7 billion \\
\hline \#Nutrition & 4 billion \\
\hline \#Addiction & 3 billion \\
\hline \#Diabetes & 2.9 billion \\
\hline \#Depressed & 2.8 billion \\
\hline \#Stress & 2.6 billion \\
\hline \#OCD & 2 billion \\
\hline \#PTSD & 1.8 billion \\
\hline \#BirthControl & 1.6 billion \\
\hline \#Bipolar & 1.6 billion \\
\hline \#STI & 1.2 billion \\
\hline \#IBS & 616.6 million \\
\hline \#HIV & 455.1 million \\
\hline \#Obesity & 499.4 million \\
\hline \#SuicidePrevention & 289.7 million \\
\hline TOta & \\
\hline
\end{tabular}

*Total number of tagged TikTok video views with a specified hashtag. Total views collected on 20 October 2021. Certain healthrelated hashtags, such as \#eatingdisorder or related terms, are blocked on the TikTok search engine and thus cannot be totalled or included.

ADHD, Attention deficit hyperactivity disorder; IBS, Irritable bowel syndrome; OCD, Obsessive-compulsive disorder; PTSD, Posttraumatic stress disorder; STI, Sexually transmitted infection.

users interact and incorporate information received into their lives and the opportunities for public health organisations to promote evidence-based information to TikTok users.

\section{Dis/misinformation spread}

Like other social media platforms, the spread of dis/misinformation is a concern on TikTok. A few studies document the spread of public health-related misinformation, on the topics of COVID- $19^{10}$ and prostate cancer. ${ }^{11}$ The extent of dis/misinformation on other topics has not yet been investigated. Research is warranted to examine dis/misinformation on all public-health and non-public health topics, including but not limited to vaccines, cancer, experimental medicine, conspiracy theories, alternative and unproven medicine, election integrity, drug/medical regulatory processes, climate change and other important topics. The role of TikTok as a platform, including the strategies or processes in place to prevent and report dis/misinformation, also warrant attention.

\section{Viewing sensitive or hateful content}

Several TikTok trends depict creators sharing personal, sometimes traumatic, stories such as surviving sexual assault, suicide or an abusive experience such as domestic violence. ${ }^{12}$ Sharing the stories, while courageous, may reach persons unprepared to view the content, such as young youth and recent survivors of the aforementioned experiences. Similarly, the person sharing such stories may not be prepared for their video becoming viral or may require support. In other cases-hateful speech, such as racism, sexism or xenophobia, may proliferate on the platform. For example, a recent report from Media Matters for America, a non-profit media watchdog group, documents how the TikTok algorithm may lead users to transphobic content. ${ }^{13}$ However, TikTok enables warnings on sensitive or graphic content, provides certain support for users ${ }^{14}$ and has banned hate speech. ${ }^{15}$ Further research is needed to evaluate the effectiveness of TikTok moderation policies, the dissemination and portrayal of sensitive topics and the experiences of users reacting to and posting such content to determine avenues of support. We encourage research from a duty to care perspective ${ }^{16}$ that strategises how to connect users to needed resources, services and follow-up when appropriate. Specific focus is needed to protect underserved groups or those that experience any form of discrimination.

\section{Problematic usage and addiction}

A speculative journalistic literature exists labelling TikTok potentially addictive. ${ }^{17}$ Research is warranted to investigate how users interact with the platform, such as attitudes towards the platform, problematic usage prevalence and facilitators, differences by age, gender and other demographic variables and evaluation of TikTok policies and initiatives to prevent and minimise overuse harms. Specific research is needed to examine the potential consequences from the algorithms underpinning the TikTok platform from ethical and regulatory perspectives.

\section{Corporate activity}

TikTok is a large for-profit business entity that requires research on their business and political activities to ensure accountability in their platform and actions. Other social media platforms, such as Facebook, are alleged to lobby governments or resist certain public health-related calls, such as moderating vaccine misinformation. ${ }^{18}$ We encourage researchers, particularly from the commercial determinants of health, to conduct research into TikTok as a corporate political actor and investigate their business practices. In making this research call, we do not make any presumption on the motives or actions of TikTok, 
but their platform size, reach, resources and influence on discourse, coupled with the historical comparison of other social media platforms and their impacts on public health, warrant attention. We urge TikTok to assist researchers by developing accessible and transparent research tools to monitor content trends, community guidelines enforcement and platform design.

\section{CONCLUSION}

TikTok has changed social media since its expeditious rise. Public health has a responsibility to examine the implications, opportunities and impacts of TikTok on health and advocate for changes where necessary. Given the rapid growth of TikTok-research is needed urgently. Particular demographics, such as young people, use TikTok at higher rates and need focused research attention to understand their app engagement and perceptions. Research should be conducted independently from TikTok and any conflicts of interests when funded by or working with TikTok declared.

Acknowledgements We wish to acknowledge Dr. Steve Mathias for his contribution to the concept of the manuscript.

Contributors All authors contributed to project conceptualisation. MZ wrote the manuscript. All authors reviewed, edited and approved the final version.

Funding The authors have not declared a specific grant for this research from any funding agency in the public, commercial or not-for-profit sectors.

Competing interests None declared.

Patient consent for publication Not applicable.

Provenance and peer review Not commissioned; externally peer reviewed.

Data availability statement No data are available.

Open access This is an open access article distributed in accordance with the Creative Commons Attribution Non Commercial (CC BY-NC 4.0) license, which permits others to distribute, remix, adapt, build upon this work non-commercially, and license their derivative works on different terms, provided the original work is properly cited, appropriate credit is given, any changes made indicated, and the use is non-commercial. See: http://creativecommons.org/licenses/by-nc/4.0/.

\section{REFERENCES}

1 Wiles K. TikTok reaches 1 billion monthly active users. MarketWatch 28 Sep 2021 [cited 2021 September 30]. Available: https://www. marketwatch.com/story/tiktok-reaches-1-billion-monthly-activeusers-11632857269
2 Russell AM, Davis RE, Ortega JM, et al. \#Alcohol: Portrayals of Alcohol in Top Videos on TikTok. J Stud Alcohol Drugs 2021;82:615-22.

3 et alJackler RK, Chau C, Getachew BD. JUUL advertising over its first three years on the market. 21 Jan 2019 [cited 2021 October 20]. Available: https://tobacco-img.stanford.edu/wp-content/uploads/ 2021/07/21231836/JUUL_Marketing_Stanford.pdf

4 Kickbusch I, Allen L, Franz C. The commercial determinants of health. Lancet Glob Health 2016;4:e895-6.

5 TikTok. Find "\#mentalhealth" on TikTok. 4 Oct 2021 [cited 2021 October 4]. Available: https://www.tiktok.com/search?q=\% 23mentalhealth\&t=1633378102988

6 Herrick SSC, Hallward L, Duncan LR. "This is just how I cope": An inductive thematic analysis of eating disorder recovery content created and shared on TikTok using \#EDrecovery. Int J Eat Disord 2021;54:516-26.

7 Fowler LR, Schoen L, Smith HS, et al. Sex education on TikTok: a content analysis of themes. Health Promot Pract 2021:152483992110315.

8 Kong W, Song S, Zhao YC, et al. TikTok as a health information source: assessment of the quality of information in diabetes-related Videos. J Med Internet Res 2021;23:e30409.

9 Zheng DX, Ning AY, Levoska MA, et al. Acne and social media: a cross-sectional study of content quality on TikTok. Pediatr Dermatol 2021;38:336-8.

10 Baumel NM, Spatharakis JK, Karitsiotis ST, et al. Dissemination of mask effectiveness misinformation using TikTok as a medium. $J$ Adolesc Health 2021;68:1021-2.

11 Xu AJ, Taylor J, Gao T, et al. TikTok and prostate cancer: misinformation and quality of information using validated questionnaires. BJU Int 2021:128:435-7.

12 Lantican F. A TikTok Trend Has People Sharing Traumatic Experiences to a Pop Song. Vice 12 Jul 2020 [cited 2021 September 30]. Available: https://www.vice.com/en/article/akdkn8/tiktok-trendshare-traumatic-experience-literally-my-life-song

13 et alLittle O, Richards A, Beecham N. TikTok's algorithm leads users from transphobic videos to far-right rabbit holes. Media Matters for America 8 Oct 2021 [cited 2021 Oct 20]. Available: https://www. mediamatters.org/tiktok/tiktoks-algorithm-leads-users-transphobicvideos-far-right-rabbit-holes

14 Porter J. TikTok to hide graphic videos behind warning screens. The Verge 2020 [cited 2021 September 30]. Available: https://www. theverge.com/2020/12/15/22175889/tiktok-updated-communityguidelines-violent-disturbing-content-warning-labels-opt-in-vaccineinfo

15 Hern A. TikTok expands hate speech ban. The Guardian 21 Oct 2020 [cited 2021 September 30]. Available: https://www.theguardian.com/ technology/2020/oct/21/tiktok-expands-hate-speech-ban

16 Gelber K. A better way to regulate online hate speech: require social media companies to bear a duty of care to users. The Conversation 2021 [cited 2021 Oct 25]. Available: http://theconversation.com/ a-better-way-to-regulate-online-hate-speech-require-social-mediacompanies-to-bear-a-duty-of-care-to-users-163808

17 DataSeries. How TikTok Is Addictive. Medium 2020 [cited 2021 September 30]. Available: https://medium.com/dataseries/howtiktok-is-addictive-1e53dec10867

18 Helmore E. Mark Zuckerberg says Facebook won't remove antivaccine posts despite Covid concerns. The Guardian $10 \mathrm{Sep}$ 2020 [cited 2021 Jul 17]. Available: http://www.theguardian.com/ technology/2020/sep/09/mark-zuckerberg-facebook-not-rightwingecho-chamber 